\title{
Loss reduction in cable sheathing
}

\author{
B. Novák ${ }^{1}$, L. Koller ${ }^{1}$ and I. Berta ${ }^{1}$ \\ ${ }^{1}$ Department of Electric Power Engineering \\ Budapest University of Technology and Economics \\ 1111 Budapest, Egry J. u 18. (Hungary) \\ phone: +361463 2904, fax: +3614633600 \\ e-mail: nbalazs@eik.bme.hu, koller.laszlo@vet.bme.hu, berta.istvan@vet.bme.hu
}

\begin{abstract}
In order to reduce electric potential difference between the sheathings of single core three-phase cables, the sheathing is grounded and bonded at one or both ends of the cables. If the cable is long, double bonding has to be carried out which leads to circulating currents and increased power loss. Based on finite element (FE) calculations, this paper shows, that raising the sheath's resistance, by decreasing its cross section and increasing its resistivity, can significantly reduce this loss. The magnetic field close to the ground surface and the behaviour of the cable during fault conditions are also investigated.
\end{abstract}

\section{Key words}

Underground cables, Losses, Finite element method.

\section{Introduction}

At the dawn of cable manufacturing lead had played a major role in cable sheathing, although its use has diminished recently because of its unfavorable mechanical properties. Instead of lead, mostly aluminum and copper has been used nowadays in underground cables, having much better mechanical characteristics and higher electrical conductivity [1, 2]. In cables, used in high voltage transmission lines, the sheathing is formed by a seamless metal envelope around the core insulation (Fig 1a); whereas in the latest cable types of medium or high voltage power distribution systems, helically applied wires embedded in a semiconductive sheathing material provide screening (Fig 1b). In order to reduce losses, the good conductivity, namely the low resistivity is a prerequisite, if a conductor must carry high amounts of current, which is true for sheathing as well. However, do high currents necessarily flow in the sheathing?

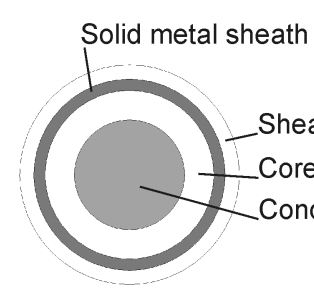

a)
Semiconductive bedding,

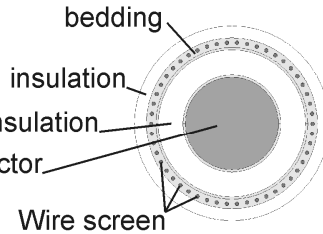

b)
Fig. 1. Single-core cables with solid metal sheath (a) and with wire screen (b).

If an AC current flows in a cable core, it induces eddy currents and emf in the metallic sheaths and in the armour of the cable. In case of single-core cables, the emf can lead to dangerous potential difference between the separate cable sheets and the ground, which can be reduced by bonding and grounding. The bonding of the sheaths at both ends of the cable generates further, circulating currents. Although these currents might play an important role in reducing the magnetic field, that is the sheaths provide magnetic shielding, as a side effect, additional losses are generated $[3,4]$. The same phenomenon occurs in such metal enclosed switchgears, where the phase conductors are enclosed separately in a metal housing. In this case, the losses in the enclosures can have the same order of magnitude as the conductor losses [5]. The losses created by the circulating currents can be eliminated by eliminating these currents themselves, which is usually achieved by cross-bonding, or by isolating the sheaths of cable sections [6], that increases installation costs. Besides the induced effects, in case of an earth fault, even larger currents can be expected, since the sheathing, if grounded at both ends of the cable, provide a path for the short circuit currents.

Now it is clear, that currents and therefore losses occur in the metal sheathing both in normal and faulty operation, which neither can be completely eliminated, nor they can be neglected, as we will see later in this article. Nonetheless, this paper tries to answer the question above, and shows, with the example of a medium (MV) and a high voltage (HV) cable, that in case of single-core cables, their magnitude can be significantly reduced by the modification of the sheathing material and thickness. All 
the results are based on 2D finite element (FE) calculations, with current or voltage excitation having a frequency of $f=50 \mathrm{~Hz}$. Current excitation was used for the modeling of symmetrical three-phase loads, since the current during normal operation is mostly determined by the impedance of the load and the electrical grid, which are much higher than that of the cables. Short circuits were modeled with voltage excitation due to the relatively higher influence of cable impedance on the current magnitude. Since the models in all the cases were linear, the results can be easily converted to other exciting current magnitudes. First we will concentrate on the losses during normal operation, since their reduction highly contributes to energy and therefore cost saving. Besides loss reduction, we have to deal with the outer magnetic field close to the soil surface, since its level must not exceed limits defined by health regulations. Finally, the modified cables will be tested in earth fault simulations.

\section{The FE cable model}

As the base of our calculations we selected one type of single core $\mathrm{MV}$ and one type of $\mathrm{HV}$ cable, with a core cross section of $A_{C}=300 \mathrm{~mm}^{2}$ corresponding with a rated current of around $I \approx 450 \mathrm{~A}$. We modeled the metal sheath (and screen) of the cable with a solid conductor pipe. As we will deal with the influence of the sheath cross section, in case of a wire screen, an equivalent thickness can represent the screen. The difference between the MV and $\mathrm{HV}$ cases were the insulation distance $\left(r_{i 1}\right)$ between the core and the sheath, and the thickness of the outer insulation $\left(r_{i 2}\right)$ (see Fig. 2). For the MV cable $r_{i 1}=5.18 \mathrm{~mm}$, and $r_{i 2}=2.5 \mathrm{~mm}$, whereas for the HV one $r_{i 1}=17.73 \mathrm{~mm}$, and $r_{i 2}=8 \mathrm{~mm}$. Since in the electromagnetic model we did not deal with dielectric losses, the insulation materials were unimportant. Both the cores and the sheaths were copper with a resistivity of $\rho_{C u}=2 \cdot 10^{-8} \Omega \mathrm{m}$. The cables were buried into the soil having a resistivity of $\rho_{G}=50 \Omega \mathrm{m}$ at a depth of $h=0.7 \mathrm{~m}$. The cables were tested in a three-phase horizontal arrangement (see Fig. 2) with a distance of $d$ between them and with the sheaths bonded and grounded at both ends. (Note: The dashed lined circle in the figure will be discussed in section 5.)

Since we modeled the soil as a conductor, the total size of the FE model was selected three times of the soil's skin depth, $\delta_{\text {soil }}$, and was terminated by elements representing infinity at the boundary. The model can be observed in Fig. 3, with a detailed part of the mesh in the vicinity of the cable.

The commercially available ANSYS ${ }^{\mathrm{TM}}$ software was used for the calculations, which allows different types of excitations of the cables. Although the running time is slightly longer than with current loading, we used symmetric voltage excitation for the simulation of the fault conditions (Fig. 4). In this case, an electrical circuit has to be defined with voltage sources supplying a symmetric voltages to the loads through the cables, the cores and sheaths of which are represented by lumped impedances. The soil is also modeled in the circuit as an impedance. By adjusting the different resistance values, different loading conditions, like asymmetric or symmetric faults or loads, can be set for the model.

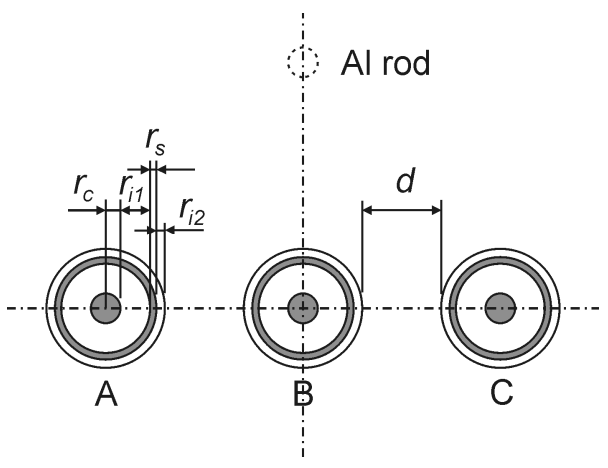

Fig. 2. The cable model.

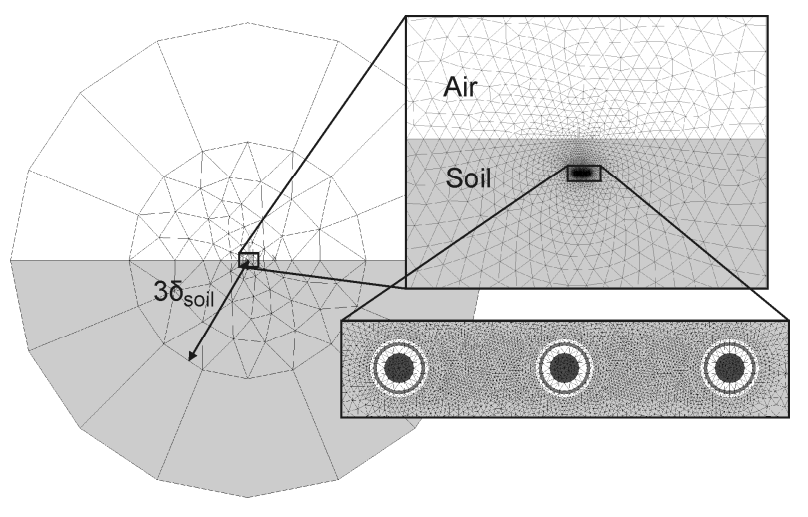

Fig. 3. FE model.

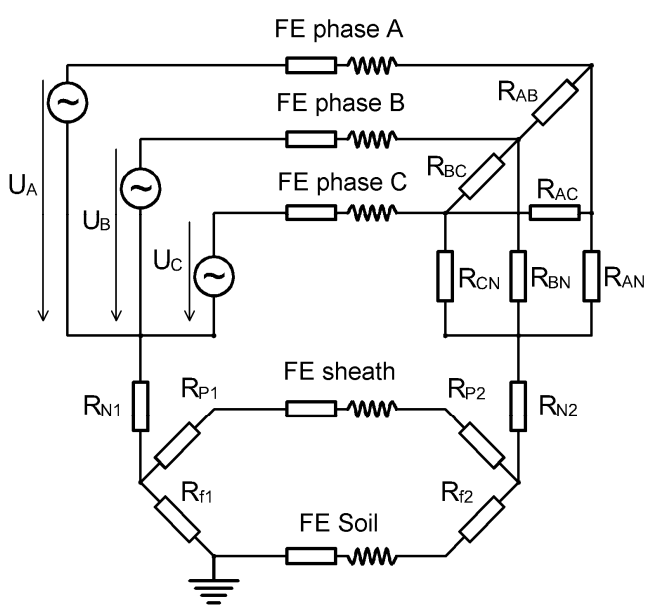

Fig. 4. Circuit diagram for voltage excitation. 


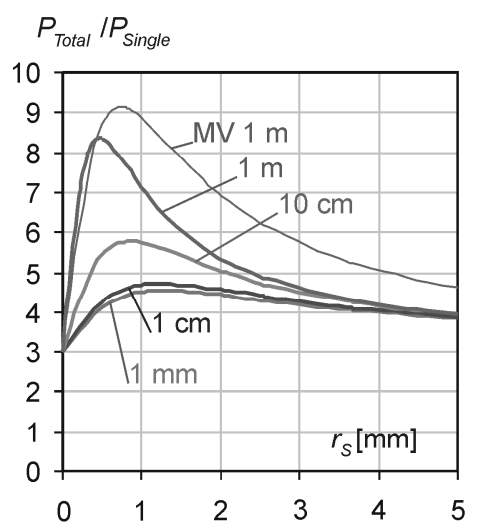

a)

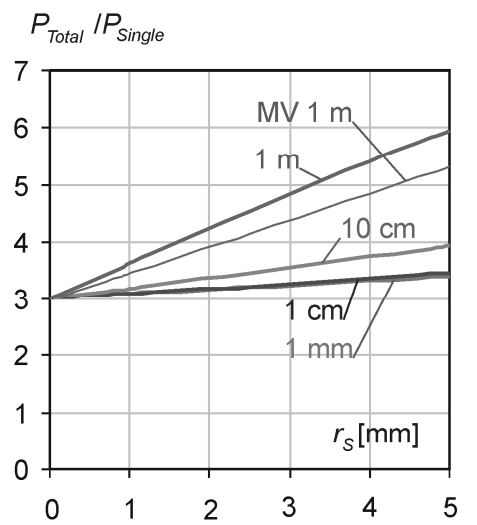

b)

Fig. 5. Variation of total loss as the function of sheath thickness in case of copper (a) and stainless steel (b) sheathing

\section{Losses in the cables}

We varied the distance $(d)$ between the cables and the thickness of the sheath $\left(r_{s}\right)$, and compared the core and sheath losses to the loss of a single conductor without any sheath $\left(P_{\text {single }}=13.75 \mathrm{~W} / \mathrm{m}\right.$ at rated current $)$, where the proximity of another conductor does not modify its AC resistance. Since the cores' radius is less than the skin depth in copper at $50 \mathrm{~Hz}$, the change in their losses, caused by the electromagnetic proximity effect was not significant compared with the change of the sheath losses, which can be in the same order of magnitude as the core losses. The ratio of the lowest and highest core losses were $P_{\text {cmin }} / P_{\text {single }}=1$ and $P_{\text {cmax }} / P_{\text {single }}=1.04$, whereas of the sheaths $P_{\text {smax }} / P_{\text {single }}=2.34$. In Fig. 5a the variation of the total losses $\left(P_{\text {tot }} / P_{\text {single }}\right)$ including all sheath and core losses can be observed as the function of $r_{s}$. Since there is no remarkable difference in the character of the variation between the two cables, only one diagram is shown with four $d$ distances for a HV and with one distance for a MV cable (thin line). It can be clearly seen that more is the distance, more are the losses at any given sheath width. This can be explained by the higher loop formed by the bonded sheaths, in which higher emf, namely higher current is induced by the core currents [3]. It is important to note that to every fixed $d$ belongs a maximum in the losses at one particular thickness, although the point of the maximum varies, it appears at thinner sheaths with higher distance. In case of the MV cable, it is shifted towards higher $r_{s}$. Very thin sheaths provide less loss that can be explained with their higher resistance due to their small cross section; the induced emf can drive only a small current through them. If the thickness is high, the resistance becomes lower, hence the lower losses. In-between, simple analytical models can explain the character of the variation, but, because of the limited length of this paper, we do not deal with this question here. It is enough to note now, that in order to reduce losses, we should select a sheath width far from the maximum. This condition is satisfied by the cables we chose as a base with a general installation distance of $d=100 \mathrm{~mm}$, since their equivalent sheath thickness is $r_{s} \approx 0.23 \mathrm{~mm}$. A slight increase of $r_{s}$ would raise the amount of losses, and a thinner copper, besides loss reduction, would degrade the mechanical strength of the cable. With power transmission cables, where the sheath is a seamless metal enclosure, $r_{s}$ is around 1.5 to $2 \mathrm{~mm}$, although it is usually made from aluminum.

We can shift the losses towards even smaller values, if we reduce the conductivity of the sheath material. For instance - just to refer to the introduction of this paper - we might replace copper with lead $\left(\rho_{P b}=2.14 \cdot 10^{-7} \Omega \mathrm{m}\right)$, or rather with non-ferromagnetic stainless steel that has even higher resistivity $\left(\rho_{S t n}=7.50 \cdot 10^{-7} \Omega \mathrm{m}\right)$. Similar to Fig. 5a, Fig. $5 \mathrm{~b}$ shows the variation of the losses with stainless steel sheathing as the function of sheath thickness.

We can see that selecting stainless steel instead of copperwith an installation distance of $100 \mathrm{~mm}$ and with the same thicknesses as with copper sheathing - can save $20 \%$ of the losses created by the currents in the cores and the sheaths. This value seems to be considerable, but what happens with the outer field during normal loading, not to mention the cable itself in case of an earth fault? We try to give an answer in the next two sections.

\section{Magnetic induction close to the ground surface}

Fig. 6a shows the variation of the highest magnetic induction $\left(B_{\max }\right) 30 \mathrm{~cm}$ above ground surface - where exposure of people has to be taken into account - as the function of sheath thickness for copper-sheathed cables with bonding at both ends and with a load of the rated current. This can be compared with similar data for stainless steel in Fig. 6b.

It is clear that we have to pay a price for the decreased losses: there is no reduction of the magnetic induction with high resistivity sheathing, as circulating currents occur in it in a much smaller degree. The same price has to be paid with cross-bonding or dividing and isolating the sheath along the cable length however, since these methods are also based on eliminating the circulating currents. In fact, magnetic shielding is not the purpose of sheathing, it has to provide mechanical protection and screening of the electric field. We can see, that even without sheathing the magnetic induction is under $100 \mu \mathrm{T}$ allowed by health regulations for people $[7,8]$. (Note: The slight increase of $B_{\max }$ in Fig. $6 \mathrm{~b}$ is due to the growth of cable diameter together with $r_{s}$ that raises the distance between cable cores.) 


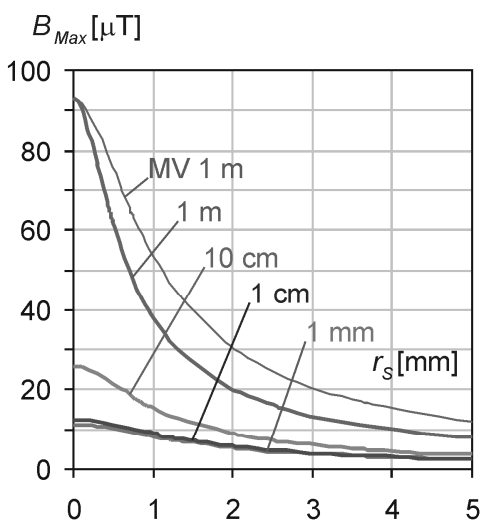

a)

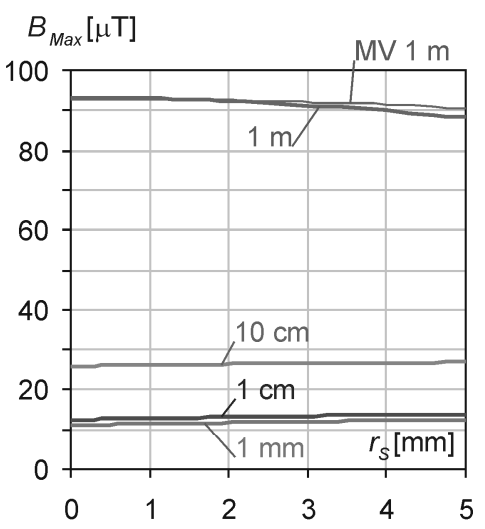

b)

Fig. 6. Variation of highest magnetic induction $30 \mathrm{~cm}$ above ground surface as the function of sheath thickness in case of copper (a) and stainless steel (b) sheathing with a symmetrical load of $450 \mathrm{~A}$.

\section{Behavior during earth fault}

Increased resistance certainly cuts down the sheath's current carrying capacity, which can be an important parameter during earth faults. Lower is this resistance higher is the fault current that it can carry without overheating. The amount of the earth fault current is determined by the earth loop impedance including the resistances and reactances of the faulty core and the bonded sheathings. One might think that increasing the sheath resistance would lower the current and power, what must be true, although the degree of this reduction is small, since the influence of the background power-grid's impedance is much more significant.

In table 1a, the losses generated by an earth fault in one of the outer cores can be compared in the cores and sheats for the traditional and for the stainless steel sheathed $\left(r_{s}=1\right.$ $\mathrm{mm}$ ) HV cable. In this case the screen of the traditional one was modeled exactly, that is, it comprised thin copper wires having a total cross section of $35 \mathrm{~mm}^{2}$. Here we present results only of the $\mathrm{HV}$ cable, since high earth currents have much less probability in a MV network. Only double earth faults in different phases at different points of the network can cause high earth currents there, due to the un-earthed neutral of the MV transformers.

For these calculations, the excitation was provided by a three-phase symmetrical voltage and the grid's impedance was taken to be $Z_{\text {grid }}=5+5 j \Omega$, where $j$ is the imaginary unit. Besides the fault, the phases were loaded by a symmetrical load of $Z_{\text {load }}=500 \Omega$. In order to consider a kind of worst case, and to take into account the grounding resistance at the end of the cables, we connected an $R_{\text {soil }}=$ $20 \Omega$ resistance serial with the soil's FE model. This results in less current in the soil, and more in the sheaths. The resulting fault current in phase $\mathrm{A}$ was around $I_{S C} \approx$ $9000 \mathrm{~A}$.

It can be clearly seen that the new cable might not be able to withstand the fault current, the power in the sheaths are six times of that in the faulty core. However, the situation is not completely hopeless. With a simple solution, by burying a metal (e.g. aluminum) rod into the soil, we can provide a path for the earth currents. The metal rod must be able to withstand the earth fault current, and, as it might not even touch the cable insulation, its temperature rise can be higher than that of a conductor inside the cable. The third column of table 1a shows the power generated in the cable components and in the rod in case of a fault. The rod was buried in the symmetry axis, $40 \mathrm{~cm}$ above the cable (see dashed circle in Fig. 2).

And what happens during symmetrical loading after this modification? Would not be the losses increased by the rod in normal operation? In table $1 \mathrm{~b}$ we can observe the losses rated to $P_{\text {single }}$ for both the conventional without, and the stainless steel sheathed cable with an earthing rod. The ratio of the total losses of the old and new cables is $P_{\text {New }} / P_{\text {Old }}=0.81$, meaning a $19 \%$ power saving.

Table 1. - Power loss in the cable components in case of a single-phase earth fault (a) and during symmetrical load (b)

(a)

\begin{tabular}{|l|r|r|r|}
\hline $\begin{array}{c}P \\
{[\mathrm{~kW} / \mathrm{m}]}\end{array}$ & $\begin{array}{c}\text { Copper } \\
\text { sheath }\end{array}$ & $\begin{array}{c}\text { Stainless } \\
\text { steel sheath }\end{array}$ & $\begin{array}{c}\text { Stainless } \\
\text { steel sheet } \\
\text { with Al rod }\end{array}$ \\
\hline Core A & 6.3851 & 6.1069 & 6.3450 \\
\hline Core B & 0.0038 & 0.0039 & 0.0046 \\
\hline Core C & $1.80 \mathrm{E}-06$ & $1.72 \mathrm{E}-05$ & $8.20 \mathrm{E}-04$ \\
\hline Sheath A & 10.3731 & 41.6529 & 3.5421 \\
\hline Sheath B & 8.1431 & 41.2328 & 1.9119 \\
\hline Sheath C & 7.8917 & 41.2049 & 1.5189 \\
\hline Al rod & - & - & 8.6003 \\
\hline Ground & 0.0000 & 0.0002 & 0.0000 \\
\hline
\end{tabular}

(b)

\begin{tabular}{|l|c|r|c|}
\hline$P / P_{\text {single }}$ & $\begin{array}{c}\text { Bonded } \\
\text { copper } \\
\text { sheath }\end{array}$ & $\begin{array}{c}\text { Bonded } \\
\text { stainless } \\
\text { steel sheet } \\
\text { with Al rod }\end{array}$ & $\begin{array}{c}\text { Non- } \\
\text { bonded } \\
\text { copper } \\
\text { sheath }\end{array}$ \\
\hline Core A & 1.0005 & 1.0005 & 1.0004 \\
\hline Core B & 1.0017 & 1.0018 & 1.0017 \\
\hline Core C & 1.0003 & 1.0003 & 1.0003 \\
\hline Sheath A & 0.3925 & 0.0729 & 0.0008 \\
\hline Sheath B & 0.1820 & 0.0408 & 0.0030 \\
\hline Sheath C & 0.3577 & 0.0685 & 0.0008 \\
\hline Al rod & - & 0.0001 & - \\
\hline Total & 3.9348 & 3.1850 & 3.0070 \\
\hline
\end{tabular}




\section{Conclusions}

In order to reduce electric potential difference between the sheathings of single core three-phase cables, the sheathing is grounded and bonded at one or both ends of the cables. If the cable is long, double bonding has to be carried out which leads to circulating currents and increased total power loss. Raising the sheath's resistance, by decreasing its cross section and increasing its resistivity, can reduce this almost to the level of the core losses. However, in case of an earth fault, a considerable portion of the fault current flows through the increased sheath resistance, creating much higher power in the sheaths than in the faulty core. A simple solution, a conductor rod buried into the soil above or under the cable can divert this power from the sheaths.

Although there are other methods for eliminating circulating currents in the sheathing, this solution provides an easy way of installation of long cables without the necessity of cross bonding or isolating the sheathing of cable sections. In our example nonferromagnetic stainless steel was selected as a sheathing material. In table $1 \mathrm{~b}$ the power losses in a double-bonded copper-, a double-bonded stainless steel- and a nonbonded copper-sheathed cable can be compared. The latter one models cross-bonding or single bonding where circulating currents cannot occur in the sheathing. Although the total losses of the new cable are $5 \%$ more than that of a non-bonded one, this difference might be further decreased by adjusting the sheath thickness and using even higher resistivity metal alloys.

\section{Acknowledgments}

This work was supported by the H-TEC Kft. (Hungarian Subsidiary of HYUNDAI Heavy Industries Co. Ltd.) by providing the FE tool for the calculations.

\section{References}

[1] Moore, G.F, Electric Cables Handbook (3rd Edition), Blackwell Publishing, 1997.

[2] R. Bartnikas, K.D. Srivastava: Power and Communication Cables - Theory and Applications, IEEE Press / McGraw Hill, 2000.

[3] G.J. Anders, Rating of Electric Power Cables: Ampacity Computations for Transmission, Distribution, and Industrial Applications, IEEE Press / McGraw Hill, 1997.

[4] I. Sarajcev, M. Majstrovic, I. Medic: Calculation of losses in electric power cables as the base of cable temperature analysis, Advanced Computational Methods in Heat Transfer, WIT Press Southampton, Boston, 2000, pp. 529537.

[5] B. Novák, L. Koller, Losses in busbars and enclosures of gas insulated switchgears, Proceedings of the 14th Conference on Computer Applications in Electrical Engineering, Poznan, Poland, May 2009. pp. 39-42.

[6] J.R. Riba Ruiz, Antoni Garcia, X. Alabern Morera, Circulating sheath currents in flat formation underground power lines, ICREPQ'07, Sevilla, Spain, 2007.

[7] ICNIRP - International Commission on Non-Ionizing Radiation Protection, Guidelines for limiting exposure to time varying electric, magnetic and electromagnetic fields (up to $300 \mathrm{GHz}$ ), Health Phys. 74 (1998) 494-522.

[8] Directive 2004/40/EC of the European Parliament and of the Council of 29 April 2004 on the minimum health and safety requirements regarding the exposure of workers to the risks arising from physical agents (electromagnetic fields) (18th individual Directive within the meaning of Article 16 (1) of Directive 89/391/EEC) European Parliament; Council of the European Union. 